\title{
UM OLHAR SOBRE A DIFERENCIAÇÃO TERRITORIAL DA POBREZA EM PORTUGAL À LUZ DA ABORDAGEM DAS CAPACIDADES DE AMARTYA SEN
}

\author{
A LOOK AT THE TERRITORIAL DIFFERENTIATION \\ OF POVERTY IN PORTUGAL IN THE LIGHT OF AMARTYA \\ SEN'S CAPABILITY APPROACH
}

\author{
Elvira Sofia Pereira \\ Centro de Administração e Políticas Públicas, Instituto Superior de Ciências Sociais e Políticas, Universidade de \\ Lisboa, Rua Almerindo Lessa, 1300-663 Lisboa, Portugal. E-mail: epereira@iscsp.ulisboa.pt
}

\begin{abstract}
Resumo: Neste artigo apresentamos um quadro de análise do papel dos contextos territoriais na configuração da pobreza, baseado na abordagem das capacidades proposta por Amartya Sen e, com recurso a observação documental de estatísticas disponibilizadas pelo Gabinete de Estatísticas da União Europeia (Eurostat), apresentamos e discutimos o panorama atual e evolução recente de indicadores e fatores relacionados com a pobreza, por grau de urbanização em Portugal, com a finalidade de contribuir para a compreensão da relação atual entre contextos territoriais e pobreza. O quadro de análise e a evidência empírica recolhida permitem identificar algumas alterações na diferenciação territorial da pobreza nos últimos 15 anos, suscitam questões sobre a validade dos indicadores padrão para medir e comparar a pobreza em diferentes contextos territoriais, sugerem uma relação complexa entre contextos territoriais e pobreza e evidenciam a importância dos contextos territoriais na configuração da pobreza.
\end{abstract}

Palavras-chave: pobreza, contextos territoriais, abordagem das capacidades, Portugal.

\begin{abstract}
In this paper, we present a framework for analyzing the role of territorial contexts in shaping poverty, based on Amartya Sen's capability approach. Using documentary observation of statistics made available by the Statistical Office of the European Union (Eurostat), we present and discuss the current panorama and recent evolution of indicators and factors related to poverty, by degree of urbanization in Portugal. This approach aims to contribute to the understanding of the relationship between territorial contexts and poverty. The framework of analysis and empirical evidence allow us to identify changes in the territorial differentiation of poverty in the last 15 years, raise questions about the validity of the standard indicators for measuring and comparing poverty in different territorial contexts, suggest a complex relationship between territorial contexts and poverty and highlight the importance of territorial contexts in shaping poverty.
\end{abstract}

Keywords: poverty, territorial contexts, capability approach, Portugal.

\section{Introdução}

Num levantamento de estudos realizados em Portugal com decomposição das medidas de pobreza por grau de ruralidade, utilizando dados entre 1980 e 2000 e diferentes critérios de identificação dos indivíduos em situação de pobreza, verificou-se 
que aqueles que utilizavam limiares não diferenciados de pobreza estimavam um risco de pobreza nas áreas rurais entre 1,5 a 3,9 vezes superior ao das zonas urbanas (Pereira, 2010a)..$^{1}$ Entre 2003 e 2016, os resultados para Portugal do indicador oficial de taxa de risco de pobreza, por grau de urbanização, apontavam para um risco entre 1,3 a 2 vezes superior nas áreas pouco povoadas (Eurostat, 2018). ${ }^{2}$

Esta evidência empírica da distribuição territorial do risco de pobreza nada revela de sistemático sobre o papel dos lugares na configuração da pobreza (Subramanian \& Duncan, 2000). Os designados estudos contextuais (Weber, Jensen, Miller, Mosley \& Fisher, 2005) contribuem para este conhecimento ao aferir a importância relativa de dois tipos de efeitos que podem explicar as diferenças observadas: o efeito da composição e o efeito estrutural. A existência de um efeito estrutural sugere que os lugares não só diferem como fazem a diferença (Subramanian \& Duncan, 2000, p. 5), configurando "um conjunto de oportunidades e barreiras" (Weber, Jensen, Miller, Mosley \& Fisher, 2005) que se diferencia no espaço.

Os resultados de um estudo contextual realizado em Portugal, utilizando os dados do Inquérito aos Orçamentos Familiares de 2000, sugerem que em Portugal contextos territoriais diferentes fazem a diferença no risco de pobreza e que é possível que uma parte importante da influência exercida pelos contextos esteja associada a oportunidades reais desiguais e escolhas individuais diferenciadas, nomeadamente ao nível da educação e do emprego, o que equivale a considerar as características socioeconómicas como variáveis intervenientes na relação entre localização e pobreza (Pereira, 2010a; 2010c).

Neste sentido, importa considerar uma eventual uma influência direta dos contextos territoriais na configuração da pobreza que é independente das características dos indivíduos, e uma influência indireta desses mesmos contextos que é mediada pelas características dos indivíduos que aí residem. Neste segundo caso, uma maior concentração de indivíduos com características de maior vulnerabilidade à pobreza em contextos territoriais "desfavoráveis", reforçada pela migração seletiva, resulta também da influência diferenciadora do contexto territorial de residência nas oportunidades e nas escolhas dos indivíduos (ver Pereira, 2010c).

Os dados mais recentes relativos aos indicadores oficiais taxa de risco de pobreza e proporção de pessoas em risco de pobreza ou exclusão social, nomeadamente entre 2010 e 2017, sugerem que em Portugal a situação permanece mais desfavorável nas áreas pouco povoadas. Por outro lado, a utilização de outros indicadores do padrão de vida e do bem-estar sugerem panoramas diferentes, associando condições mais desfavoráveis aos contextos mais urbanos (áreas densamente povoadas). Por exemplo, em Portugal, a taxa de privação material severa observada nas áreas densamente povoadas é superior à observada nas áreas pouco povoadas, à semelhança do que acontece 
noutros países europeus com taxas de privação severa mais baixas (Eurostat, 2011). Weziak-Bialowolska (2016), utilizando um índice de pobreza multidimensional operacionalizado com dados do Inquérito às Condições de Vida e Rendimento (ICOR) da União Europeia de 2011, observa que em Portugal a situação globalmente mais desfavorável associa-se às áreas densamente povoadas, à semelhança do que acontece na Grécia e na Itália e ao contrário do que acontece noutros países com pobreza elevada ou moderadamente elevada.

Alguns estudos (ver Milbourne, 2014; Milbourne \& Doheny, 2012), sugerem a existência de relações complexas entre pobreza e lugares, evidenciando desconexões importantes entre "as dimensões materiais e socioculturais da pobreza" nas zonas rurais do país de Gales. Em Portugal, registam-se evidências semelhantes de desconexões entre dimensões do bem-estar (ver Pereira, Queiroz, Pereira \& Vicente, 2005).

Estes dados e estudos sugerem assim a necessidade de aprofundar a compreensão da relação entre contextos territoriais e pobreza em Portugal, suscitando em particular quatro questões exploratórias: i) Terão ocorrido, nos últimos 15 anos, alterações na diferenciação territorial observada da pobreza?; ii) Será que alguns (dos indicadores utilizados para observar a pobreza têm baixa validade e fiabilidade?; iii) É a relação que se estabelece entre contextos territoriais e pobreza complexa, com coexistência de fatores de vulnerabilidade/exclusão e fatores de proteção/inclusão nos diferentes contextos, e assim difícil de observar na sua globalidade?; e IV) $\mathrm{Na}$ atualidade, contextos territoriais diferentes fazem a diferença na pobreza em Portugal?

Considerando que a pobreza é um problema social macro sobretudo explicado por oportunidades económicas e sociais limitadas (Cotter, 2002), neste artigo propomo-nos apresentar um quadro de análise do papel dos contextos territoriais na configuração da pobreza, baseado na abordagem das capacidades de Amartya Sen e, seguindo um desenho descritivo-comparativo, com recurso a observação documental de estatísticas disponibilizadas pelo Gabinete de Estatísticas da União Europeia (Eurostat), apresentar e discutir o panorama atual e evolução recente de indicadores e fatores relacionados com a pobreza, por grau de urbanização, e assim contribuir para a compreensão da relação atual entre contextos territoriais e pobreza.

A primeira parte do artigo é assim dedicada à apresentação do quadro analítico referido, de seguida são apresentados os aspetos metodológicos subjacentes à observação documental e numa terceira parte são apresentados e discutidos os resultados da observação documental realizada. O artigo termina com algumas considerações finais. 


\section{O papel dos contextos territoriais na configuração da pobreza visto à luz da abordagem das capacidades de Amartya Sen}

Apesar de criticada por alguns por ser demasiado individualista, a abordagem das capacidades de Amartya Sen reconhece justamente a influência dos contextos sociais nas realizações alcançadas pelos indivíduos (Robeyns, 2005). Acresce que, ao considerar diferentes espaços (bases informacionais) na avaliação e conceptualização da pobreza e do padrão de vida, permite desenvolver um quadro de análise abrangente da influência dos contextos territoriais na configuração da pobreza nesses diferentes espaços.

De uma forma geral, Sen $(1981 / 1999 ; 1983 ; 1992)$, distingue e relaciona seis espaços ou bases informacionais: (1) rendimento, (2) bens, (3) características dos bens, (4) capacidade ou oportunidades reais para realizar funcionamentos, (5) funcionamentos, e (6) utilidade ou satisfação. O rendimento permite a obtenção de bens, os bens possuem determinadas características, estas características conferem aos indivíduos, dados os seus fatores de conversão, uma determinada capacidade, a escolha associada ao exercício dessa capacidade traduz-se na realização de funcionamentos e a realização desses funcionamentos origina um determinado nível de utilidade ou satisfação. De acordo com o autor, os três primeiros espaços têm um valor instrumental e os três últimos têm valor intrínseco, sendo que o espaço mais adequado na avaliação e conceptualização da pobreza é o da capacidade, uma vez que indica o que uma pessoa pode ser ou fazer, refletindo as oportunidades reais da pessoa para levar a vida que com razão valoriza.

Nesse sentido, quer os funcionamentos quer a satisfação, ambos com valor intrínseco, são bases informacionais preteridas. No primeiro caso, porque resulta de uma escolha, no segundo caso, pelo facto de a mesma poder ser demasiado desligada da natureza da vida que as pessoas levam e influenciada pelo condicionamento mental e atitudes adaptativas tornando-se "maleável demais para constituir-se um guia confiável para a privação e a desvantagem" (Sen, 1999/2000, p. 82).

Da mesma forma, os espaços com valor instrumental apenas, nomeadamente o rendimento privado, são preteridos como bases informacionais dado que a grande heterogeneidade dos seres humanos, expressa em características individuais e em circunstâncias externas, implica a existência de diferenças substanciais na conversão do rendimento e recursos pessoais em funcionamentos (Sen, 1992; 1999/2000). Uma avaliação centrada no rendimento é, contudo, admitida como forma de observar a capacidade individual para realizar funcionamentos que deste dependem desde que as variações sistemáticas entre rendimento e capacidade sejam consideradas.

Uma vez que a pobreza, em particular, é observada ao nível do agregado doméstico privado, admitindo partilha de recursos no seio do mesmo, estas variações 
sistemáticas podem ser agrupadas em duas categorias principais: a dimensão e a composição do agregado doméstico privado (características individuais) e as características dos locais onde residem (circunstâncias externas), ou na terminologia usada neste artigo, o contexto territorial de residência.

Num artigo que sintetiza os resultados da literatura sobre a influência dos contextos territoriais de residência na pobreza, Blank (2005) identifica cinco atributos de uma região ou localidade que podem influenciar a incidência e a natureza da pobreza: i) o ambiente natural, ii) a estrutura económica, iii) as instituições comunitárias e políticas, iv) as normas sociais e o ambiente cultural e v) as características demográficas da população. Estes atributos estão relacionados entre si. Por exemplo, uma economia local que fornece oportunidades de emprego limitadas e associadas a baixas qualificações pode reforçar as baixas habilitações locais através da influência que produz sobre as ambições educacionais dos que aí residem, uma vez que os jovens perante oportunidades de emprego com baixas qualificações não investem na formação, e pela seleção residencial dos que ficam, uma vez que os indivíduos mais dotados tenderão a abandonar essas áreas à procura de melhores oportunidades de emprego (Blank, 2005). Esta situação tem como consequência a erosão da base dos recursos locais, o que por sua vez influenciará as oportunidades económicas futuras e a atração de novos investimentos e empresas (Blank, 2005; Ravallion, 1998).

Considerando os atributos do lugar identificados por Blank e quatro das bases informacionais identificadas por Amartya Sen e as respetivas relações, a figura 1, adaptada de Robeyns (2005), ilustra o efeito estrutural que os contextos territoriais podem ter na configuração da pobreza dos indivíduos.

Desde logo, o contexto territorial pode ter uma influência importante no rendimento privado que os indivíduos conseguem obter. As oportunidades de geração de rendimento, nomeadamente em termos de trabalho e emprego, e o valor de rendimento associado, nomeadamente salário e outros rendimentos do trabalho, podem variar substancialmente entre contextos territoriais diferentes. Esta diferença pode transmitir-se para a reforma, admitindo que os indivíduos não mudam de local de residência, dado que as pensões de reforma dependem, pelo menos em parte, dos rendimentos do trabalho obtidos durante a vida ativa.

A quantidade/qualidade de bens e serviços que se pode comprar com um determinado nível de rendimento pode também diferir de acordo com o contexto territorial. Torna-se assim necessário ter em conta as diferenças territoriais do custo de vida, considerando os preços e os bens disponíveis, uma vez que estes afetam o poder de compra de um determinado rendimento. É possível que existam aqui alguns trade-offs. O custo da habitação (para proprietários e arrendatários) pode ser 


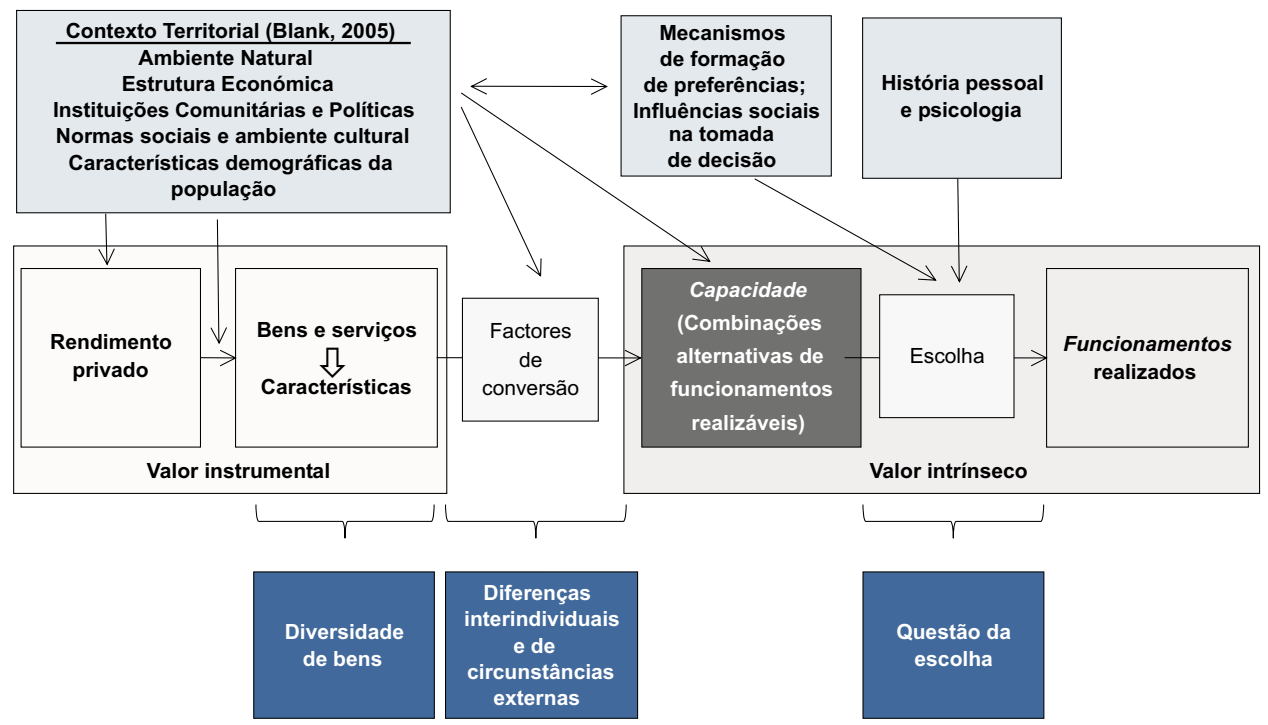

Figura 1 papel dos contextos territoriais à luz da abordagem das capacidades de Amartya Sen

mais elevado nalguns contextos territoriais, sendo compensado, pelo menos em parte, por custos de transporte mais baixos nesses mesmos contextos.

Os contextos territoriais podem também influenciar os fatores de conversão, aliás algumas das fontes de variação a ter em conta na conversão de rendimento em capacidade, (os designados fatores de conversão) identificadas por Sen estão inequivocamente associadas a atributos dos contextos territoriais tais como identificados por Blank (2005), nomeadamente: i) variações nas condições ambientais (ambiente natural), ii) variações intersociais nos bens necessários para realizar funcionamentos fundamentais (normas sociais e ambiente cultural); e iii) variações no acesso a bens de consumo coletivo e a bens de consumo individual (instituições comunitárias e políticas).

Assim, a capacidade para realizar alguns funcionamentos pode também exigir níveis de rendimento diferentes em contextos territoriais diferentes, ora porque existe uma variação sistemática dos bens ou da quantidade requerida dos mesmos, ora porque existe uma variação sistemática dos bens e serviços a que os agregados domésticos podem ter acesso fora do mercado, ou seja, para além daqueles que podem obter com o seu rendimento. Por exemplo, funcionamentos como sentir-se respeitado e integrado podem exigir bens e serviços diferentes em diferentes 
contextos territoriais. Como salienta Sen (1999/2000), "as necessidades de mercadorias associadas a padrões de comportamento estabelecidos podem variar entre comunidades, dependendo de convenções e costumes" (p. 91). Por outro lado, a disponibilização local de bens de consumo coletivo ou individual tornam independente do rendimento privado a realização de alguns funcionamentos, configurando recursos económicos que acrescem ao rendimento obtido pelos indivíduos.

Existem também, como referido, fatores de conversão relacionados com as características dos agregados, nomeadamente a sua dimensão e a sua composição. Assim, é necessário ter simultaneamente em conta: i) as necessidades relativas de rendimento de indivíduos com características diferentes, por exemplo, idade e sexo, ii) os efeitos das economias de escala no consumo para agregados com mais do que um indivíduo e iii) a distribuição intrafamiliar dos recursos. Embora estes fatores de conversão não correspondam a circunstâncias externas ao agregado, podem interagir com estas de diferentes formas. Por exemplo, a variação das circunstâncias externas pode ter efeitos diferenciados, em termos de conversão do rendimento em funcionamentos, conforme o grupo etário dos indivíduos e a distribuição intrafamiliar dos meios sancionada pelas normas sociais e ambiente cultural.

A influência do contexto territorial de residência no rendimento obtido, na quantidade/qualidade dos bens que pode ser obtida com esse rendimento e na sua conversão em capacidades cujo exercício depende (pelo menos em parte) de recursos económicos dá conta da sua importância na configuração da pobreza a montante.

Mas o contexto territorial de residência pode também exercer influência mais diretamente sobre os funcionamentos realizados, ao exercer influência direta sobre a capacidade e a escolha. Reconhecer esta influência é importante, por um lado, porque tem implicações sobre a forma como a pobreza é vivida no quotidiano, por outro, porque determinadas escolhas, nomeadamente ao nível da educação e do emprego, têm implicações presentes e futuras na configuração da pobreza a montante. Em particular, pelo efeito que podem ter quer na configuração dos territórios quer nas oportunidades individuais de obtenção de rendimento.

De facto, por exemplo, as características das relações e laços sociais associadas a diferentes contextos territoriais podem ser determinantes para a capacidade de realizar funcionamentos complexos como o de sentir-se respeitado e integrado. ${ }^{3}$ Neste caso, o rendimento não substitui nem pode substituir os "recursos sociais" necessários para alcançar determinados funcionamentos. Assim, estas diferenças poderão originar diferenciações territoriais nos níveis de capacidade, funcionamentos e satisfação que não conseguem ou podem ser compensadas por níveis diferentes de rendimento.

De uma forma geral, o argumento central é de que o bem-estar dos indivíduos, traduzido na capacidade para realizar funcionamentos que os indivíduos com 
razão valorizam, depende não só do rendimento e das condições materiais, mas também de outros recursos e condições não materiais, de que os primeiros não são substitutos, que variam com os contextos, e que influenciam a qualidade de vida dos indivíduos.

Neste sentido, este quadro de análise ilustra também a importância de ir além das condições materiais de vida que determinam a situação de pobreza para os aspetos relacionais da experiência de pobreza (Lister, 2015) para compreender melhor o papel dos contextos territoriais na configuração da pobreza.

A satisfação com a vida ou o bem-estar subjetivo, que é tanto um espaço de avaliação do padrão de vida, tal como identificado por Amartya Sen, como um funcionamento valorizado em muitas sociedades (estar satisfeito com a vida que se leva), depende de vários fatores que não se esgotam nas condições materiais, incluindo quer outras circunstâncias objetivas de vida (Boarini, Comola, Smith, Manchin \& Keulenaer, 2012) quer os quadros de referência e os processos de adaptação individuais (OECD, 2013). Em particular, o conhecimento que o indivíduo tem das circunstâncias atuais dos indivíduos com os quais se compara, nomeadamente os do(s) seu(s) grupo(s) de referência, e as suas próprias circunstâncias anteriores funcionam como quadros de referência na avaliação e apreciação das suas circunstâncias de vida atuais. Na medida em que os contextos territoriais podem configurar quadros de referência para os indivíduos que aí residem, este é um outro aspeto a considerar na análise da influência daqueles na forma como a situação de pobreza é vivida no quotidiano.

Finalmente, o quadro analítico da abordagem das capacidades permite evidenciar não só os constrangimentos estruturais, associados aos contextos territoriais, que incidem sobre as oportunidades reais, mas também a influência destes contextos nas escolhas realizadas pelos indivíduos. Importa aqui convocar, em particular, a literatura que procura estudar a influência da cultura no comportamento (escolhas) dos indivíduos em situação de pobreza. Small, Harding e Lamont (2011) sugerem a utilização de sete ferramentas analíticas diferentes: valores, frames, repertórios de estratégias e ações, narrativas, limites simbólicos, capital cultural e instituições.

Em particular, o repertório de estratégias e ações que os indivíduos conhecem (melhor), a designada caixa de ferramentas (Swidler, 1986), sendo moldado pelos contextos de socialização, é uma ferramenta analítica que pode ser mobilizada para compreender uma parte das diferenças territoriais nas escolhas que os indivíduos realizam. Por um lado, "é improvável que os indivíduos se envolvam em uma ação a não ser que a estratégia para a executar faça parte do seu repertório" (Small, Harding \& Lamont, 2011, p. 102), ou seja, os indivíduos tendem a mobilizar as 
ferramentas que lhes são (mais) familiares para prosseguir os fins que valorizam. Por outro lado, os indivíduos acabam por valorizar (preferir) os fins e as alternativas para as quais consideram ter as ferramentas adequadas (Swidler, 1986).

\section{Aspetos metodológicos}

Tendo em conta o quadro de análise proposto do papel dos contextos territoriais na configuração da pobreza, seguindo um desenho descritivo-comparativo, este artigo reúne alguma evidência quantitativa de indicadores selecionados relacionados com a pobreza e o bem-estar, por grau de urbanização, com o objetivo de descrever o seu panorama atual e a sua evolução recente (últimos 15 anos) e contribuir para a compreensão da relação entre os contextos territoriais e a pobreza na atualidade em Portugal.

A pobreza é entendida neste trabalho como uma "situação de recursos económicos insuficientes para obter o padrão de vida mínimo aceite ou largamente aprovado como tal" (Pereira, 2010a, p. 25). Reconhece-se, contudo, que existem outros aspetos que devem ser considerados na observação do bem-estar e da pobreza dos indivíduos uma vez que estes influenciam as vivências quotidianas da situação de pobreza.

A evidência foi sobretudo recolhida através de observação documental de estatísticas disponibilizadas on-line pelo Eurostat e agrupa-se em duas áreas principais relacionadas com as bases informacionais identificadas na abordagem das capacidades de Amartya Sen: a) rendimento e privação forçada de bens e serviços e b) capacidades, funcionamentos e satisfação.

A tabela 1 discrimina as várias séries de dados utilizadas, agrupadas por área, e o respectivo código on-line.

A fonte primária dos dados da grande maioria das séries utilizadas é o Inquérito às Condições de Vida e Rendimento (ICOR), realizado anualmente desde 2004, e alguns dos módulos ad-hoc anuais do mesmo. Duas das séries de dados, nomeadamente o abandono precoce de educação e formação e a população por nível de escolaridade completo mais elevado, têm como fonte primária o Inquérito ao Emprego (IE).

Com algumas exceções, nomeadamente as séries de dados associadas a módulos ad-hoc do ICOR, a janela de observação corresponde à série temporal de dados completa até 2017: no caso das variáveis relacionadas com o rendimento, os dados têm como referência os anos de 2003 a 2016 (ano anterior ao inquérito), no caso das outras variáveis, os dados têm como referência os anos de 2004 a 2017 (ano do inquérito).

Todas as séries de dados selecionadas apresentam-se desagregadas por grau de urbanização. Oindicador de grau de urbanização disponibilizado pelo Eurostat 
Tabela 1 Séries de dados utilizadas e respetivos códigos on-line

\begin{tabular}{|c|c|c|}
\hline Área & $\begin{array}{l}\text { Designação das séries de dados } \\
\text { Mediana do rendimento monetário líquido por adulto equivalente } \\
\text { Taxa de risco de pobreza } \\
\text { Taxa de risco de pobreza depois de custos com a habitação } \\
\text { Taxa de privação material } \\
\text { Taxa de privação material severa } \\
\text { Taxa de privação material e social } \\
\text { Necessidades não satisfeitas de consulta a um médico (autoapreciação) } \\
\text { por razão principal } \\
\text { Necessidades não satisfeitas de consulta a um dentista (autoapreciação) } \\
\text { por razão principal } \\
\text { Necessidades não satisfeitas de educação formal (auto-apreciação) } \\
\text { por razão principal } \\
\text { Dificuldade de acesso a transportes públicos }\end{array}$ & $\begin{array}{l}\text { Código on-line } \\
\text { ilc_di17 } \\
\text { ilc_li43 } \\
\text { ilc_li48 } \\
\text { n.a. } \\
\text { ilc_mddd23 } \\
\text { ilc_mdsd09 } \\
\text { hlth_silc_21 } \\
\text { hlth_silc_22 } \\
\text { ilc_ats08 } \\
\text { ilc_hcmp06 }\end{array}$ \\
\hline $\begin{array}{l}\text { Capacidades, } \\
\text { funcionamentos } \\
\text { e satisfação }\end{array}$ & $\begin{array}{l}\text { Satisfação média com diversas dimensões da vida } \\
\text { Estado de saúde (auto-apreciação) } \\
\text { Abandono precoce de educação e formação } \\
\text { População por nível de escolaridade completo mais elevado }\end{array}$ & $\begin{array}{l}\text { ilc_pw02 } \\
\text { hlth_silc_18 } \\
\text { edat_Ifse_30 } \\
\text { edat_lfs_9913 }\end{array}$ \\
\hline
\end{tabular}

classifica as freguesias de Portugal em três categorias: áreas densamente povoadas, áreas medianamente povoadas e áreas pouco povoadas. Esta classificação, que se baseia essencialmente em critérios de dimensão populacional, densidade populacional e contiguidade, foi introduzida em 1991, mas o método de classificação foi revisto em 2011. Nesta revisão, a observação destes critérios ao nível das freguesias foi substituída pela análise da distribuição populacional dentro destas unidades utilizando células de $1 \mathrm{~km} 2$ (Dijkstra \& Poelman, 2014). Esta revisão foi implementada a partir de 2012 nos inquéritos onde era usada e deve ser tida em conta na análise realizada na janela temporal considerada neste artigo, uma vez que os dados antes e depois desta data não são totalmente comparáveis, estando assinalados como uma quebra de série. ${ }^{4}$

Na apresentação e discussão do panorama atual e evolução recente, na próxima secção deste artigo, é descrito e comparado o perfil territorial, considerando as três categorias de território identificadas, que resulta da utilização de cada um dos indicadores selecionados, interpretando os resultados no contexto do quadro teórico e analítico apresentado na secção anterior.

Nunca é demais salientar que os indicadores são em geral medidas imperfeitas e incompletas daquilo que efetivamente pretendemos observar. Os procedimentos metodológicos associados à construção dos indicadores utilizados para observar a pobreza e as limitações das opções que lhes estão subjacentes têm sido discutidos de forma aprofundada na literatura (ver, entre outros, Guio, Gordon, Nahera \& Pomati, 2017; Pereira, 2010a) e não cabe neste artigo uma discussão pormenorizada destas questões. Contudo, importará identificar em particular 
alguns problemas relacionados com a validade e a fiabilidade destes indicadores na observação da pobreza, sobretudo quando existem implicações relevantes para as comparações realizadas entre diferentes categorias territoriais. Assim, na apresentação realizada dos resultados, na próxima secção deste artigo, serão identificadas algumas limitações dos indicadores, recomendando-se uma interpretação cautelosa dos resultados em termos do perfil territorial da pobreza.

Finalmente, importa salientar que todos os dados apresentados configuram estimativas pontuais com um erro associado, que não é disponibilizado para as séries utilizadas. Existem, contudo, informações sobre o cálculo e os valores do erro padrão para os principais indicadores de pobreza e exclusão social, que são disponibilizadas nos relatórios de qualidade do ICOR e noutras publicações do Eurostat (Atkinson, Guio \& Marlier, 2017; Osier, Berger \& Goedemé, 2013). Tendo em conta essas informações, é necessário também interpretar com alguma cautela quer as variações observadas na janela temporal considerada quer as diferenças entre as categorias territoriais, em particular as de menor valor.

\section{Pobreza, privação, satisfação e oportunidades reais nos diferentes contextos territoriais em Portugal}

Os três primeiros indicadores de observação selecionados - rendimento monetário líquido anual mediano, taxa de risco de pobreza e taxa de risco de pobreza depois de custos da habitação - baseiam-se na variável designada por rendimento monetário líquido por adulto equivalente observada num determinado ano civil, o imediatamente anterior ao da realização do inquérito, que designaremos, no restante artigo, por rendimento equivalente. $\mathrm{O}$ rendimento equivalente resulta da divisão do rendimento monetário líquido observado ao nível do agregado por um índice de necessidades relativas que tem em conta quer a dimensão quer a composição do agregado, sendo utilizada para este efeito a escala de equivalência modificada da OCDE. ${ }^{5}$

Assinalam-se aqui duas limitações desta variável na observação da pobreza que podem ter implicações importantes para as comparações realizadas entre diferentes categorias territoriais, recomendando assim cautela na interpretação dos resultados obtidos com a utilização dos indicadores nela baseados. Em primeiro lugar, exclui-se da observação o rendimento não monetário, em particular o associado ao autoconsumo e à autolocação. A exclusão destas componentes de rendimento não monetário, com relevância diferenciada para indivíduos com características diferentes e em contextos territoriais diferentes, pode introduzir um enviesamento na comparação que se realiza do rendimento e das taxas de risco de pobreza entre diferentes 
contextos territoriais (Pereira, 2010a). Em segundo lugar, alguns estudos realizados na Europa têm sugerido a inadequação dos ponderadores implícitos na escala de equivalência modificada da OCDE para estimar as necessidades relativas de rendimento de agregados com diferentes dimensões e composições, com níveis de rendimento abaixo da mediana (em Portugal, ver Pereirinha, Pereira, Branco, Amaro, Costa \& Nunes, 2017). Assim, tendo em conta uma composição demográfica diferenciada nas diferentes áreas, esta opção pode igualmente introduzir uma distorção no perfil territorial da pobreza.

De acordo com os dados do ICOR, entre 2003 e 2016 (anos de referência dos dados), a mediana do rendimento equivalente nas áreas densamente povoadas foi sempre superior à observada nas áreas pouco povoadas, observando-se genericamente uma relação direta entre rendimento mediano e grau de urbanização (figura 2).

Nas três áreas a mediana do rendimento equivalente aumentou entre 2003 e 2016, mas nas áreas densamente povoadas esse aumento terá sido menor (tendo em conta separadamente a evolução registada entre 2003 e 2010 e entre 2011 e 2016), o que justifica uma pequena redução da diferença observada no rendimento mediano entre áreas densamente povoadas e áreas pouco povoadas.

O indicador oficial taxa de risco de pobreza identifica a percentagem de indivíduos com rendimento equivalente inferior ao limiar de risco de pobreza, que se convencionou a nível europeu corresponder a $60 \%$ do valor mediano do rendimento equivalente observado no país nesse mesmo ano. No mesmo período de observação, a taxa de risco de pobreza nas áreas densamente povoadas foi sempre inferior à taxa de risco de pobreza observada nas áreas pouco povoadas e, até 2011, observa-se uma relação inversa entre taxa de risco de pobreza e grau de urbanização (figura 3). Em 2016, contudo, a taxa de pobreza mais baixa é observada nas áreas medianamente povoadas.

Considerando a existência de uma quebra de série associada ao ano 2011, estes dados parecem evidenciar uma mudança diferenciada nas taxas de risco de pobreza nas diferentes categorias de território. Assinala-se, assim, uma redução em 5,3 pontos percentuais na taxa de pobreza nas áreas pouco povoadas entre $2003 \mathrm{e}$ 2010, e uma redução em 3,4 pontos percentuais nas áreas muito povoadas entre 2003 e 2008. Entre 2011 e 2016, assinala-se uma redução em 2,1 pontos percentuais nas áreas pouco povoadas e um aumento em 3,2 pontos percentuais nas áreas muito povoadas, mantendo, neste último caso, uma tendência de aumento já observada entre 2009 e 2010.

Estes dados sugerem assim uma convergência das taxas de risco de pobreza observadas por grau de urbanização, justificada por uma redução sustentada da taxa de pobreza nas áreas pouco povoadas e um agravamento, possivelmente conjuntural, da taxa de pobreza nas áreas densamente povoadas a partir de 2008. 


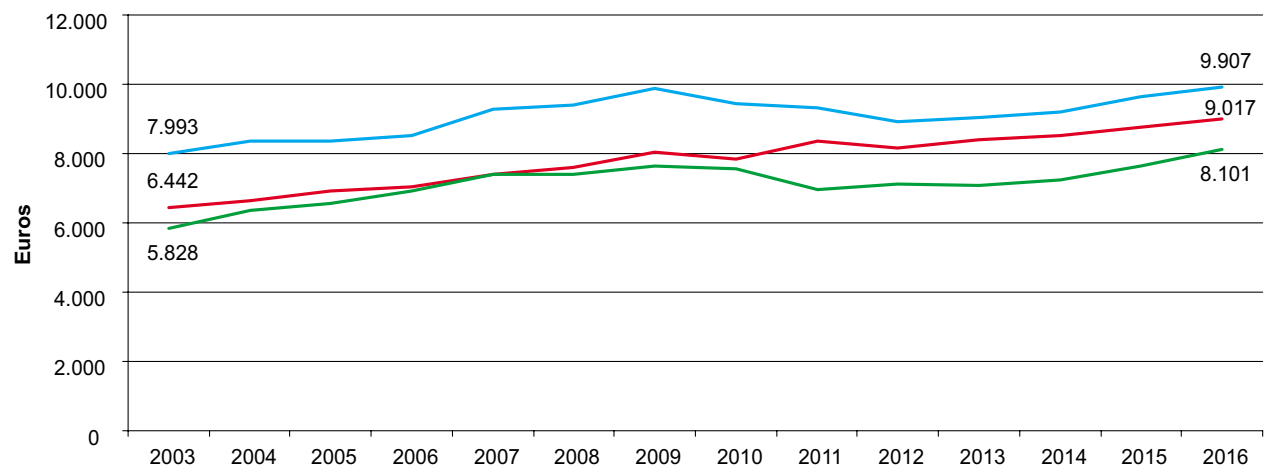

— Áreas densamente povoadas _ _ Áreas medianamente povoadas _ Áreas pouco povoadas

Figura 2 Mediana do rendimento monetário líquido por adulto equivalente em Portugal

Notas: Quebra de série em 2011.

Fonte dos dados: ICOR 2004 a 2017.

Fonte: Eurostat, julho de 2018 [código on-line ilc_di17].

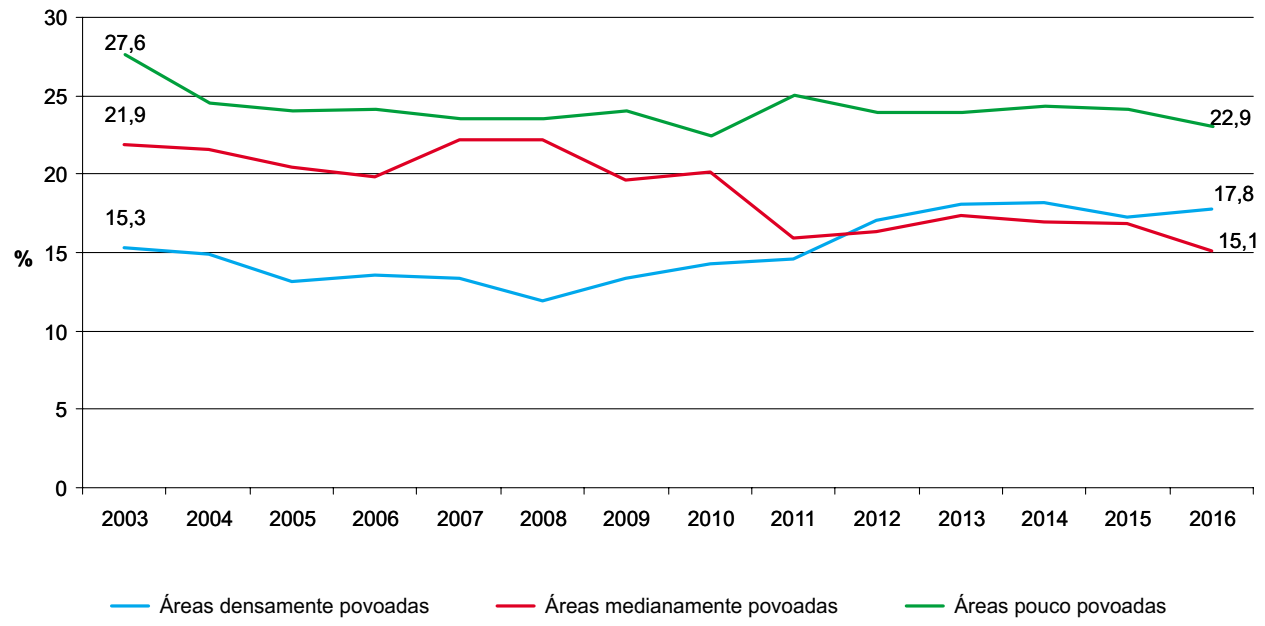

Figura 3 Taxa de risco de pobreza em Portugal

Notas: Quebra de série em 2011.

Fonte dos dados: ICOR 2004 a 2017.

Fonte: Eurostat, julho de 2018 [código on-line ilc_li43]. 
A diferenciação territorial do rendimento e da taxa de risco de pobreza apresentada não tem em conta eventuais variações territoriais no custo de vida que são importantes para a observação do padrão de vida que pode ser obtido com um determinado valor de rendimento. Uma das diferenças que pode ser relevante considerar, tendo em conta que é uma despesa inescapável com um peso considerável para a maioria dos agregados (Pereira, 2010a), é a variação das despesas com a habitação. Nesse sentido, importa apresentar também os dados relativos à taxa de risco de pobreza depois de deduzir os custos com a habitação. ${ }^{6}$ Neste caso, ao rendimento monetário líquido do agregado são deduzidas as despesas com a habitação antes de o transformar em rendimento equivalente, e são identificados como estando em risco de pobreza os indivíduos cujo rendimento equivalente depois de deduzir os custos com a habitação é inferior a $60 \%$ do rendimento equivalente mediano. ${ }^{7}$

O panorama de diferenciação territorial evidenciado por este indicador é relativamente semelhante ao anterior (figura 4).

De facto, a taxa de pobreza depois de deduzir os custos com a habitação observada nas áreas densamente povoadas mantém-se sempre inferior à observada nas áreas pouco povoadas. Ao longo da janela temporal de observação, verifica-se também uma redução na diferença entre ambas. Assinala-se, em particular, uma redução em 6 e 2,1 pontos percentuais na taxa de pobreza nas áreas pouco povoadas, respetivamente entre 2003 e 2010 e entre 2011 e 2016. Ao contrário, nas áreas densamente povoadas regista-se um aumento tendencial, possivelmente conjuntural, da taxa de risco de pobreza entre 2008 e 2014.

Estes dados evidenciam também os efeitos do aumento substancial das taxas de juro de referência na área euro, utilizadas como indexantes nos empréstimos à habitação, em particular em 2006 e 2007, e da sua queda em 2008.

Oconjunto destes três indicadores parece sugerir uma diminuição da diferenciação territorial no espaço do rendimento na janela temporal de observação, embora se verifique ainda uma situação potencialmente mais desfavorável nas áreas pouco povoadas. Tendo em conta os dados apresentados, esta convergência pode ser associada, em parte, a um efeito diferenciado da recente crise económica na pobreza, mais penalizador para as áreas densamente povoadas, traduzido num maior aumento das taxas de risco de pobreza nestas áreas entre 2008 e 2014. Se esta diminuição das diferenças for efetivamente sobretudo explicada pela conjuntura de crise, é expectável que a diferenciação volte a aumentar com a recuperação económica.

O segundo conjunto de três indicadores - taxa de privação material, taxa de privação material severa e taxa de privação material e social - relaciona-se com a observação da privação material no espaço dos bens. A adoção deste tipo de indicadores no seio da União Europeia é em grande parte justificada pelo descontentamento com o 


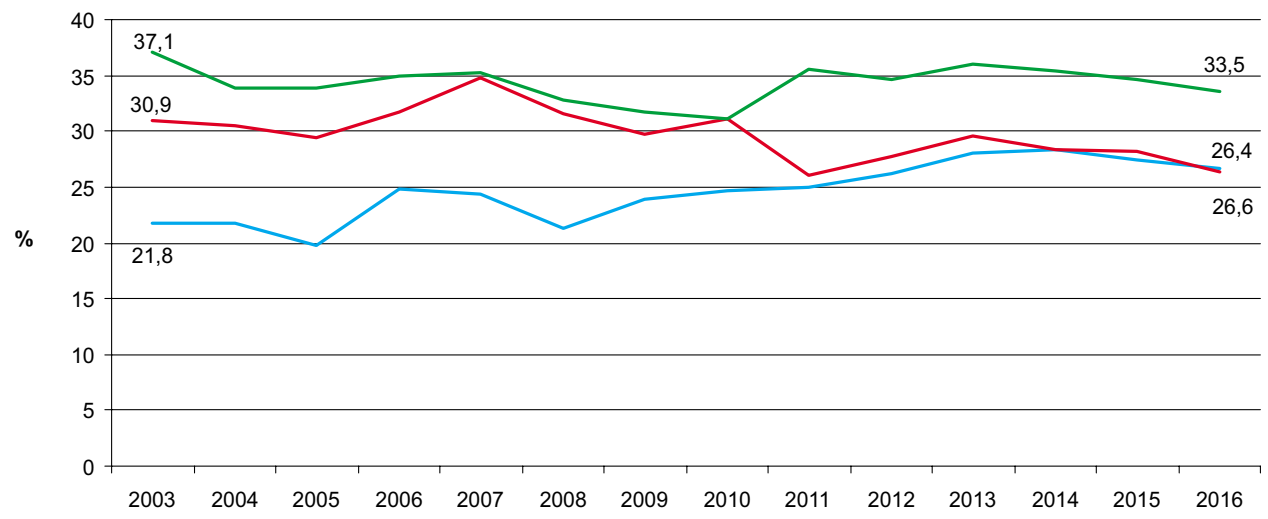

— Áreas densamente povoadas _ _ Áreas medianamente povoadas _ Áreas pouco povoadas

Figura 4 Taxa de risco de pobreza depois de deduzir os custos com a habitação em Portugal

Notas: Quebra de série em 2011.

Fonte dos dados: ICOR 2004 a 2017.

Fonte: Eurostat, julho de 2018 [código on-line ilc_li48].

indicador monetário oficial de pobreza, como indicador único, e pela necessidade de observar a privação material, complementarmente à observação do rendimento, para melhorar o diagnóstico e a compreensão da pobreza (Pereira, 2010b).

A observação da privação material no espaço dos bens coloca, contudo, desafios particulares associados à construção de indicadores adequados, tendo em conta, entre outros, a diversidade de bens que podem ser utilizados para satisfazer uma mesma necessidade (bens substitutos), as diferenças interindividuais e de circunstâncias externas que originam diferenças nos bens necessários para indivíduos diferentes, com circunstâncias externas diferenciadas, e a dificuldade de distinguir a privação forçada por insuficiência de recursos, por um lado, da privação ligada à escolha, por outro (Pereira, 2010a, pp. 221-229).

A taxa de privação material e a taxa de privação material severa, respetivamente adotadas em 2009 e 2010, baseiam-se no mesmo conjunto de nove itens para observar a privação material. ${ }^{8} \mathrm{~A}$ primeira corresponde à percentagem de indivíduos privados em, pelo menos, três dos nove itens e a segunda corresponde à percentagem de indivíduos privados em, pelo menos, quatro dos nove itens. A taxa de privação material e social foi adotada mais recentemente, em 2017, e inclui treze itens (Guio, Gordon, Nahera \& Pomati, 2017). ${ }^{9}$ Esta taxa corresponde à percentagem de indivíduos privados em, pelo menos, cinco dos treze itens selecionados. 
Mais uma vez, a interpretação dos resultados obtidos com estes indicadores deve ser realizada com cautela, dados os diversos problemas identificados na literatura relacionados com a validade e a fiabilidade destas medidas (Guio, Gordon, Nahera \& Pomati, 2017; Pereira, 2010a). Em primeiro lugar, o problema colocado pela utilização de um mesmo conjunto de itens, em qualquer um dos indicadores referidos, para aferir a privação de agregados compostos por indivíduos com características diferentes, em termos por exemplo de idade, e a residir em contextos territoriais diferenciados, cujas preferências podem diferir substancialmente. ${ }^{10}$ De facto, a existência de uma relevância diferenciada destes itens para agregados com características internas e circunstâncias externas diferentes pode originar distorções no perfil territorial observado da privação (Pereira, 2010a, pp. 100-101; 251-258). De uma forma mais geral, as respostas dadas, em termos de distinção entre privação por dificuldades económicas ou privação por outras razões, podem refletir diferenças de preferências, em particular, as que resultam da adaptação a condições económicas desfavoráveis (Guio, Gordon, Nahera \& Pomati, 2017; Pereira, 2010a, p. 100-101). Finalmente, nalguns dos itens, observados ao nível do agregado, verificou-se que uma mudança no indivíduo do agregado que responde ao questionário pode originar mudanças significativas na resposta que é dada (Guio, Gordon, Nahera \& Pomati, 2017, p. 18).

De acordo com os dados do ICOR, entre 2004 e 2009, a relação entre taxa de privação material e grau de urbanização inverteu-se (INE, 2010). ${ }^{11}$ De facto, em 2004 observa-se uma relação inversa entre a taxa de privação material e o grau de urbanização, com uma taxa de privação nas áreas pouco povoadas 4,4 pontos percentuais superior à observada nas áreas densamente povoadas. Já em 2009, os dados sugerem uma relação direta entre privação e urbanização, com a taxa de privação material nas áreas densamente povoadas 5,2 pontos percentuais superior à taxa observada nas áreas pouco povoadas (figura 5).

A alteração observada neste período é justificada pelo aumento em 2,8 pontos percentuais da taxa de privação nas áreas densamente povoadas e uma redução em 6,8 pontos percentuais nas áreas pouco povoadas.

Já a taxa de privação material severa observada entre 2004 e 2017, evidencia uma privação sempre superior nas áreas densamente povoadas relativamente à observada nas áreas pouco povoadas, sendo que esta diferença excedeu os 2 pontos percentuais entre 2008 e 2015 (figura 6). O maior agravamento desta taxa nas áreas densamente urbanas verifica-se em 2013.

A taxa de privação material e social, disponibilizada apenas na janela temporal de 2014 a 2017, indica também uma maior privação nas áreas densamente 


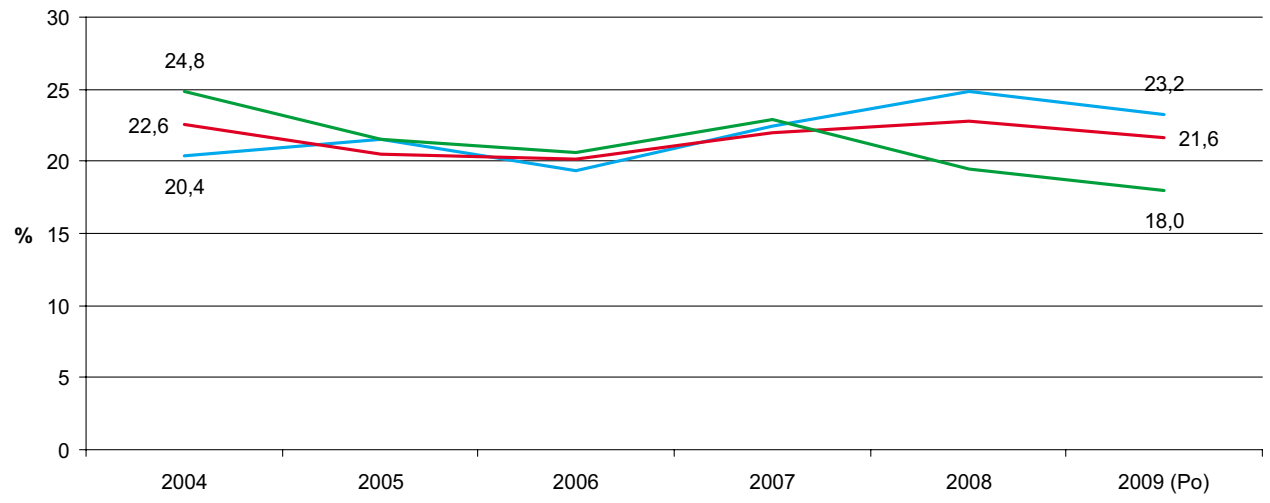

— Áreas densamente povoadas _ Áreas medianamente povoadas _ Áreas pouco povoadas

Figura 5 Taxa de privação material em Portugal

Fonte dos dados: ICOR 2004 a 2009.

Fonte: INE, 2010.

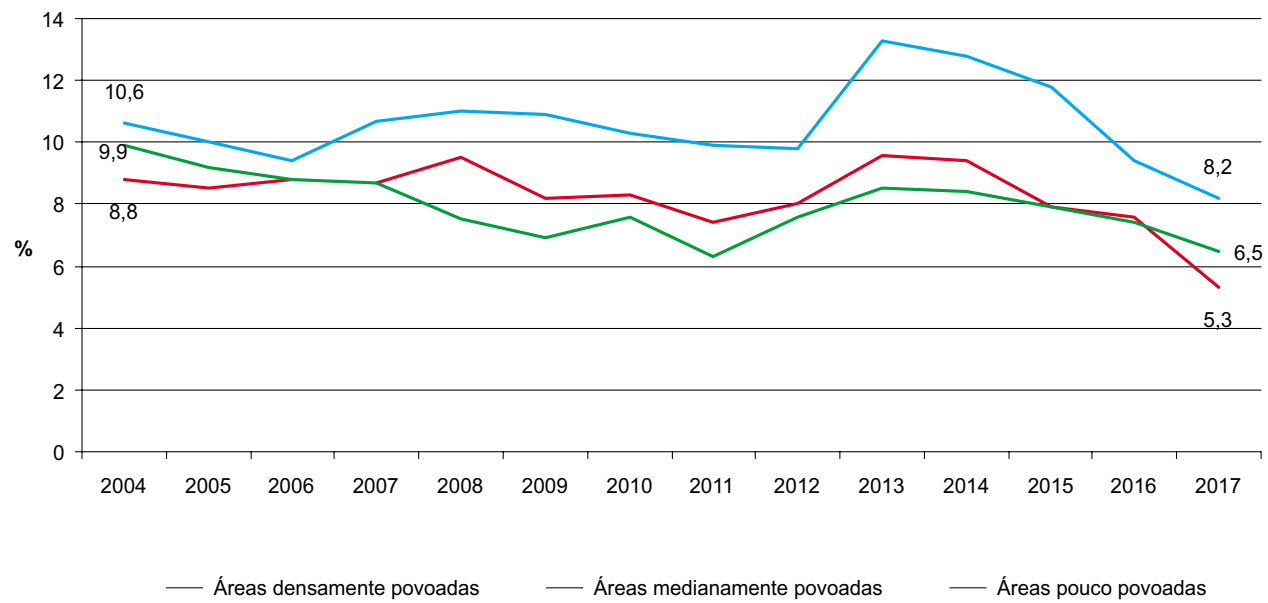

Figura 6 Taxa de privação material severa em Portugal

Notas: Quebra de série em 2012.

Fonte dos dados: ICOR 2004 a 2017.

Fonte: Eurostat, julho de 2018 [código on-line ilc_mddd23]. 
povoadas relativamente às áreas pouco povoadas em todos os anos de observação. Em 2017, o valor era de 18,7\% para as primeiras e 15,8\% para as segundas. As áreas medianamente povoadas registavam neste mesmo ano a taxa mais baixa: $15,2 \%$.

Este segundo conjunto de indicadores sugere uma situação mais desfavorável nas áreas densamente povoadas, com diferenças assinaláveis na taxa de privação entre áreas densamente povoadas e áreas pouco povoadas sobretudo entre 2008 e 2015, evidenciando também aqui os já referidos efeitos territoriais diferenciados da recente crise económica na pobreza, mais penalizadores para as áreas densamente povoadas.

O facto de a observação da privação sugerir um panorama diferente relativamente ao observado no espaço do rendimento monetário configura uma aparente incoerência entre os indicadores utilizados na observação da pobreza. Por um lado, esta aparente incoerência pode refletir os efeitos de diferenças no rendimento não monetário auferido, nomeadamente o autoconsumo, de diferenças no custo de vida, para além das que resultam das despesas com a habitação, e, mais genericamente, dos fatores de conversão territorialmente diferenciados do rendimento privado em capacidade para realizar funcionamentos. ${ }^{12}$ Neste caso, a observação do rendimento monetário, sem incorporar essas variações sistemáticas de forma adequada, pode subestimar relativamente a capacidade dos indivíduos/agregados residentes em áreas pouco povoadas para obter o padrão de vida mínimo aceite ou largamente aprovado como tal. Por outro lado, esta aparente incoerência pode ser um reflexo dos problemas metodológicos que se colocam na observação da pobreza recorrendo a indicadores de privação forçada, por inadequação de recursos económicos, relativamente a esse padrão de vida (Guio, Gordon, Nahera \& Pomati, 2017; Pereira, 2010a). Neste caso, a observação da privação pode sobrestimar relativamente a capacidade dos indivíduos/agregados residentes em áreas pouco povoadas para obter o padrão de vida mínimo aceite ou largamente aprovado como tal em Portugal. Em ambos os casos, a incoerência suscita questões sobre a validade destes indicadores padrão para medir e comparar a pobreza em diferentes contextos territoriais. ${ }^{13}$

Para além daqueles indicadores, importará observar a privação no acesso a serviços, não considerados naqueles, que podem ser condicionados pela disponibilidade local dos mesmos, tendo em conta assim não só a falta de capacidade económica para obtê-los, mas também a inexistência de oferta nas proximidades e/ou a falta de transportes ou a distância. Estes fatores, que podem variar entre contextos territoriais, influenciam a conversão do rendimento em bens e serviços e, por sua vez, em capacidades para realizar funcionamentos. 
Os dados relativos a necessidades não satisfeitas de consulta a um médico e a um dentista (autoapreciação) para os indivíduos com 16 ou mais anos entre 2012 e 2017 sugerem uma maior privação na satisfação destas necessidades nas áreas pouco povoadas relativamente à observada nas áreas densamente povoadas, sobretudo no caso do dentista onde se regista em 2017 uma diferença de 4,6 pontos percentuais (figura 7).

Considerando as razões apontadas para a não satisfação das necessidades de consulta nas áreas pouco povoadas em 2017, no caso de consulta a um médico (5\%), cerca de metade devia-se a falta de disponibilidade financeira (demasiado caro) e ser demasiado longe ou falta de meio de transporte, respetivamente $2,5 \%$ e $0,1 \%$, no caso de consulta a um dentista $(17,7 \%)$ a grande maioria devia-se igualmente a estas duas razões, respetivamente, $14 \%$, e $0,1 \%$.

Os dados relativos a necessidades não satisfeitas de educação formal (auto-apreciação) para os indivíduos com 16 ou mais anos, observados no módulo ad-hoc do ICOR de 2016, ilustram em particular a importância da disponibilidade/adequação dos serviços. Quer nas áreas pouco povoadas quer nas áreas densamente povoadas, cerca de $40 \%$ da população sem frequência de algum ano ou nível de escolaridade (ou curso de formação com equivalência a níveis de ensino) indicou não desejá-lo (não necessita). A maior diferença entre categorias territoriais nas razões indicadas para a não frequência verifica-se na inexistência de cursos ou programas apropriados. Nas áreas densamente povoadas esta razão é indicada por 4,5\% dos indivíduos e nas áreas pouco povoadas esta é a razão indicada por $16,9 \%$. Se considerarmos em conjunto a falta de capacidade económica e a inexistência de cursos ou programas apropriados, a privação observada por estas duas razões é superior nas áreas pouco povoadas relativamente à observada nas áreas densamente povoadas, respetivamente $28,2 \%$ e $22,4 \%$.

Para os indivíduos com rendimento inferior ao limiar de pobreza, a privação observada por estas duas razões correspondia a cerca de $32 \%$ em ambas as áreas, destacando-se a falta de capacidade económica nas áreas densamente povoadas $(26,9 \%)$ e a inexistência de cursos ou programas apropriados nas áreas pouco povoadas $(21,1 \%)$.

Finalmente, em termos de dificuldade de acesso a transportes públicos, única variável relacionada com acessibilidade dos serviços básicos do módulo ad-hoc do ICOR de 2012 disponibilizada desagregada por grau de urbanização, a dificuldade é claramente maior nas áreas pouco povoadas. De facto, nas áreas pouco povoadas, $23,3 \%$ da população classificou o acesso como muito difícil $(7,8 \%)$ ou algo difícil $(15,5 \%)$, e nas áreas densamente povoadas o valor correspondente foi de $11,1 \%$ 


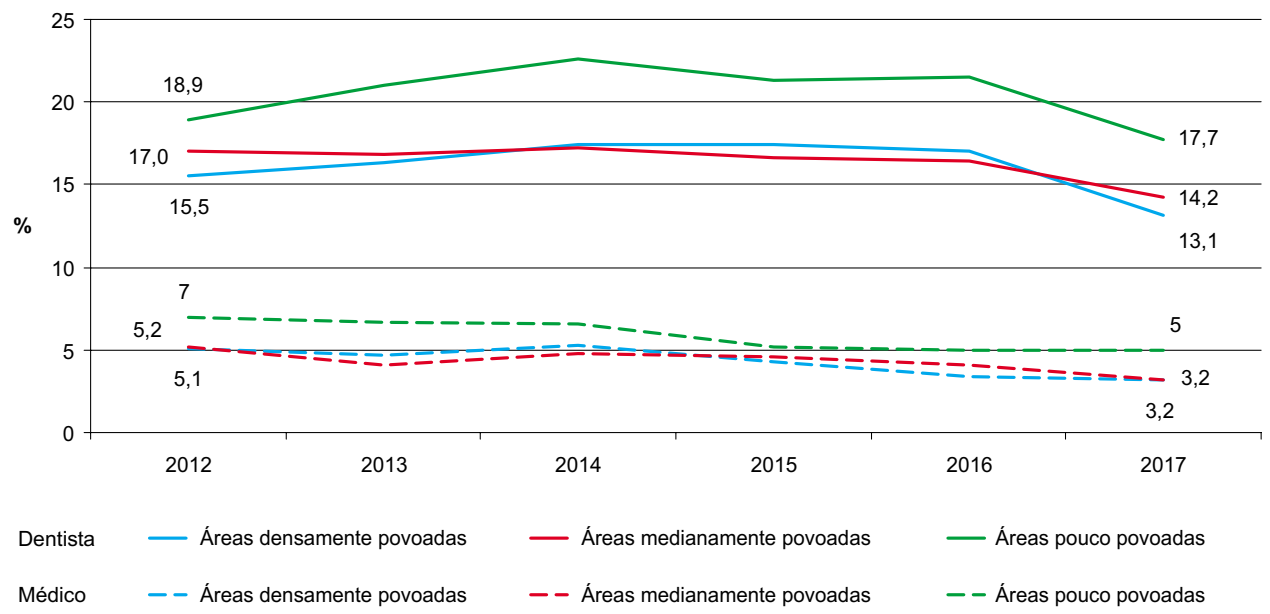

Figura 7 Necessidades não satisfeitas de consulta (dentista e médico) em Portugal Fonte dos dados: ICOR 2012 a 2017.

Fonte: Eurostat, julho de 2018 [código on-line hlth_silc_21; hlth_silc_22].

( $1,9 \%$ consideraram muito difícil e $9,8 \%$ algo difícil). Também no $1^{\circ}$ quintil de rendimento equivalente, que corresponde de forma aproximada à população em risco de pobreza (nesse ano, a taxa de risco de pobreza era de 18,7\%), a proporção da população a considerar o acesso como muito difícil ou algo difícil nas áreas pouco povoadas correspondia a cerca do dobro da proporção observada nas áreas pouco povoadas, respetivamente $27,9 \%$ e $13,9 \%$.

Estes indicadores adicionais, associados a necessidades ou funcionamentos generalizadamente valorizados, sugerem, no seu conjunto, uma maior privação material forçada nas áreas pouco povoadas.

\section{Capacidades, funcionamentos e satisfação}

Os dados do módulo ad-hoc do ICOR de 2013 sobre a satisfação com diversas dimensões da vida, observada para os indivíduos com 16 ou mais anos, não indicam diferenciações relevantes por grau de urbanização, com exceção da satisfação com a área de residência no que respeita a acessos e equipamentos (comércio, transportes públicos e equipamentos recreativos e culturais), onde se verifica uma menor satisfação nas áreas pouco povoadas (figura 8).

Observando os mesmos indicadores, apenas para o $1^{\circ}$ quintil do rendimento equivalente, que corresponde de forma aproximada à população em risco de 


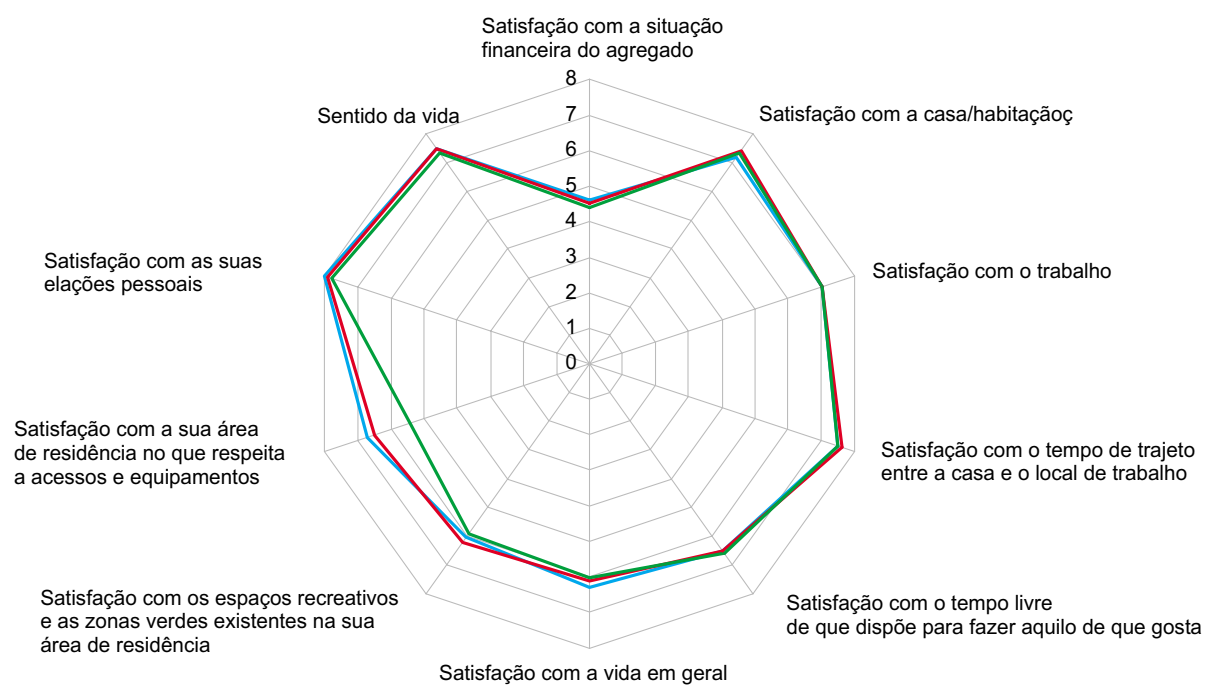

— Áreas densamente povoadas _ _ Áreas medianamente povoadas _ Áreas pouco povoadas

Figura 8 Satisfação com diversas dimensões da vida, pontuação média do total da população em Portugal em 2013

Fonte dos dados: ICOR 2013.

Fonte: Eurostat, abril de 2017 [código on-line ilc_pw02].

pobreza (nesse ano, a taxa de risco de pobreza era de 19,5\%), o panorama altera-se um pouco (figura 9).

Assim, embora, tal como se verifica para a média da população, a satisfação com a área de residência no que respeita a acessos e equipamentos seja inferior nas áreas pouco povoadas, é de destacar uma maior satisfação nas áreas pouco povoadas com a situação financeira do agregado em relação às áreas medianamente e densamente povoadas e com a vida geral em relação às áreas medianamente povoadas.

No seu conjunto, os dados até aqui apresentados sugerem diferenças entre contextos territoriais na conversão de rendimento monetário em funcionamentos e satisfação. Além de poderem refletir algumas das limitações já referidas na utilização do rendimento monetário equivalente para observar a pobreza, estas diferenças podem também ser explicadas quer por outras circunstâncias objetivas de vida, para além das condições materiais, quer pelos quadros de referência associados a diferentes contextos territoriais. Neste caso, os contextos das áreas pouco povoadas podem funcionar, de certa forma, como fatores de proteção/inclusão dos indivíduos identificados como estando em situação de risco de pobreza, por referência 


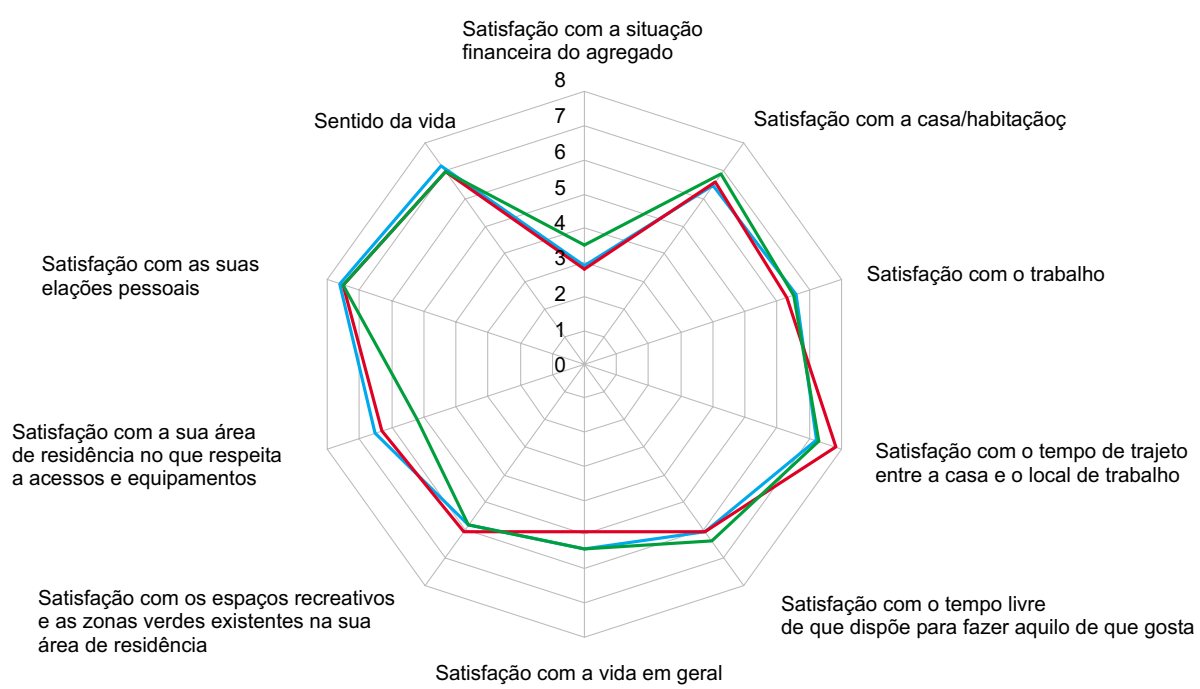

— Áreas densamente povoadas _ _ Áreas medianamente povoadas _ _ Áreas pouco povoadas

Figura 9 Satisfação com diversas dimensões da vida, pontuação média do $1^{\circ}$ quintil de rendimento equivalente em Portugal em 2013

Fonte dos dados: ICOR 2013.

Fonte: Eurostat, abril de 2017 [código on-line ilc_pw02].

a um padrão nacional (correspondente à mediana do rendimento monetário líquido por adulto equivalente em Portugal).

Ainda assim, e embora a satisfação seja um funcionamento valorizado em muitas sociedades (estar satisfeito com a vida que se leva), como refere Sen (1999/2000) o espaço da satisfação é "maleável demais para constituir-se um guia confiável para a privação e a desvantagem" (p. 82). Importa por isso observar indicadores associados a outros funcionamentos, nomeadamente na área da saúde e da educação, que podem não só indicar desigualdades territoriais nas oportunidades reais para se levar a vida que com razão se valoriza, mas que têm também implicações na configuração da pobreza a montante pelo efeito que podem ter quer na configuração dos territórios quer nas oportunidades individuais de obtenção de rendimento.

De acordo com os dados do ICOR, entre 2004 e 2017, a percentagem de indivíduos com 16 ou mais anos que avaliam o estado geral de saúde como muito bom ou bom foi sempre superior nas áreas densamente povoadas relativamente às áreas pouco povoadas, sendo a situação em 2017 muito semelhante à observada em 2004, com uma diferença de aproximadamente 10 pontos percentuais entre estas duas zonas (figura 10). 


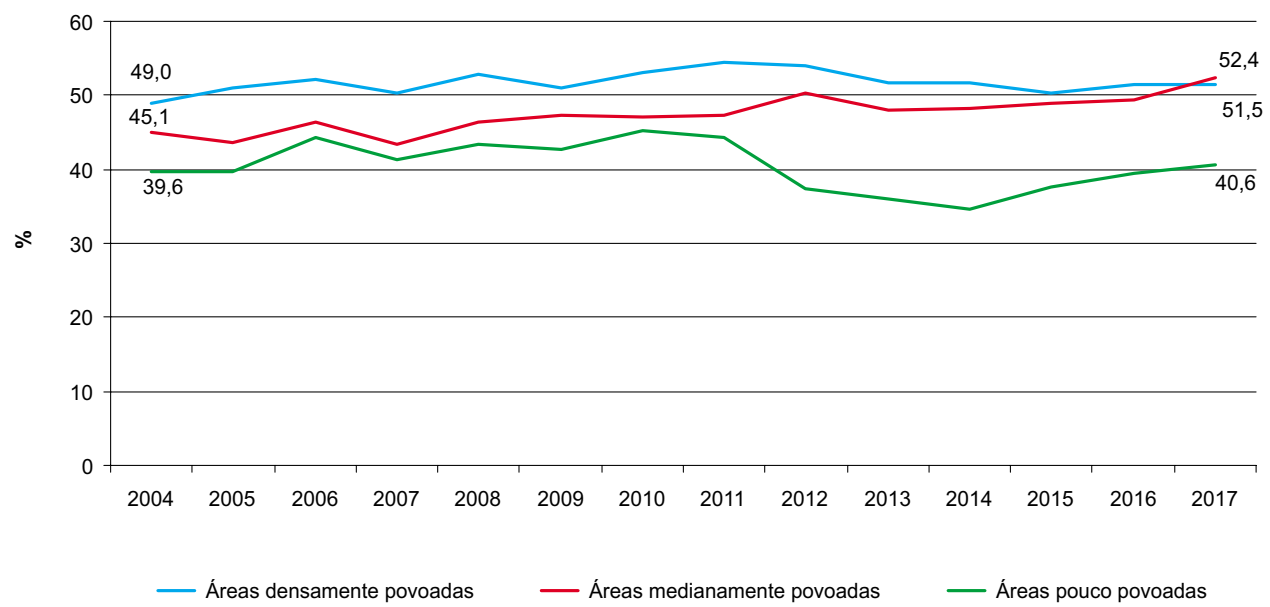

Figura 10 Autoapreciação do estado geral de saúde como Muito Bom ou Bom em Portugal

Notas: Qiebra de série em 2012.

Fonte dos dados: ICOR 2004 a 2017.

Fonte: Eurostat, julho de 2018 [código on-line hltc_silc18].

Os dados para a população com 65 ou mais anos indicam um panorama semelhante, com uma maior percentagem de indivíduos com 65 ou mais anos a avaliar o seu estado de saúde como muito bom ou bom nas áreas densamente povoadas relativamente à observada nas áreas pouco povoadas em toda a janela temporal. Em 2017 em particular, regista-se uma diferença de 8,5 pontos percentuais entre estas categorias territoriais neste grupo etário. Estes dados sugerem assim uma situação mais desvantajosa nas áreas pouco povoadas, independente do eventual efeito diferenciador da estrutura etária.

A taxa de abandono escolar precoce, que corresponde à percentagem da população entre os 18 e os 24 anos que completou no máximo o $3^{\circ}$ ciclo do ensino básico (ISCED 2) e que não recebeu nenhum tipo de educação no período de referência, pode ser igualmente utilizada como indicador das oportunidades reais para realizar funcionamentos generalizadamente valorizados. A observação deste indicador entre 2004 e 2017 revela uma situação de desvantagem nas áreas pouco povoadas relativamente às áreas densamente povoadas (figura 11).

De facto, nos diferentes contextos territoriais esta taxa reduziu-se substancialmente, mas, na maioria dos anos que compõem a janela temporal, a taxa de abandono precoce de educação e formação foi superior nas áreas pouco povoadas em mais de 2 pontos percentuais relativamente à observada nas áreas densamente 


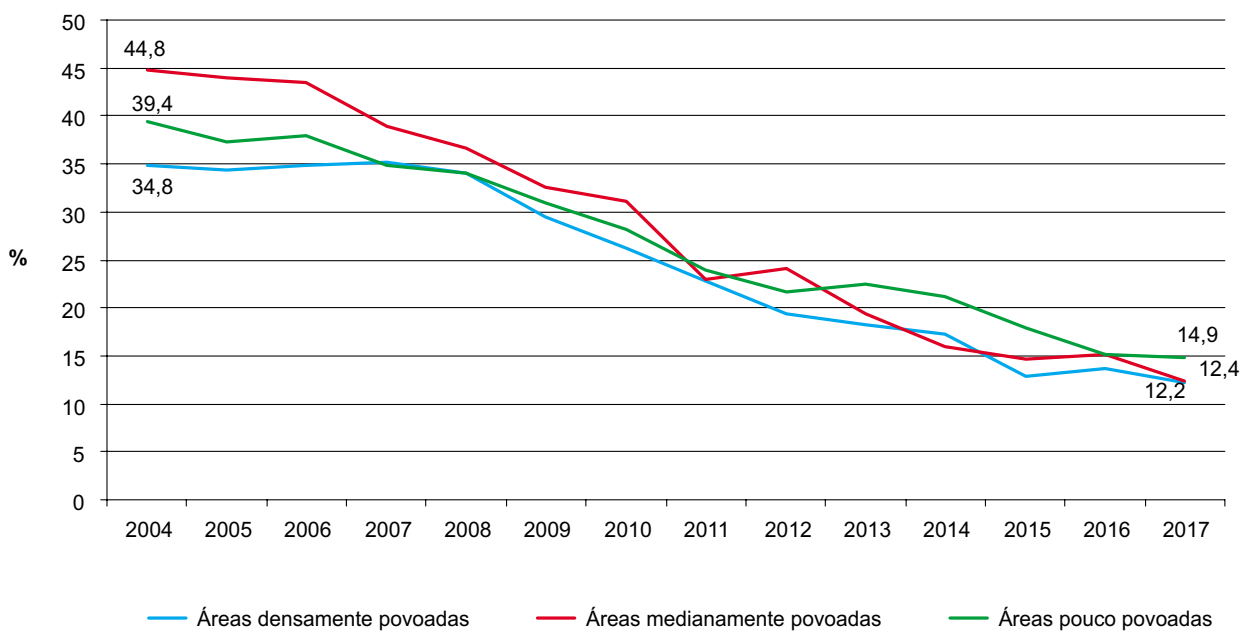

Figura 11 Taxa de abandono precoce de educação e formação

Notas: quebra de série em 2012

Fonte dos dados: ICOR 2004 a 2017.

Fonte: Eurostat, julho de 2018 [código on-line edat_lfse_30].

povoadas. Assinala-se que a categoria territorial com maior taxa de abandono escolar precoce entre 2004 e 2010 era a das áreas medianamente urbanas.

Entre 2004 e 2017, o indicador qualificação superior da geração mais jovem em Portugal, que corresponde à proporção de pessoas entre os 30 e os 34 anos que completaram o ensino superior ou equivalente (ISCED 5-8), revela uma diferenciação territorial mais clara a que corresponde a uma menor qualificação nas áreas pouco povoadas relativamente à observada nas áreas densamente povoadas (figura 12).

Neste caso, a diferença alargou-se, de 9,2 pontos percentuais em 2004 para 18,5 pontos percentuais em 2017. Em termos relativos, a proporção de pessoas entre os 30 e os 34 anos que completaram o ensino superior ou equivalente (ISCED 5-8) era 1,8 vezes superior nas áreas densamente povoadas em 2004 relativamente ao observado nas áreas pouco povoadas e 2 vezes superior em 2017.

O conjunto dos dados relativos à educação sugerem assim uma situação de maior desvantagem nas áreas pouco povoadas relativamente às áreas densamente povoadas e, considerando os dados relativos à qualificação superior da geração mais jovem, um agravamento dessa desvantagem relativa, com implicações, presentes e futuras, na configuração da pobreza a montante. 


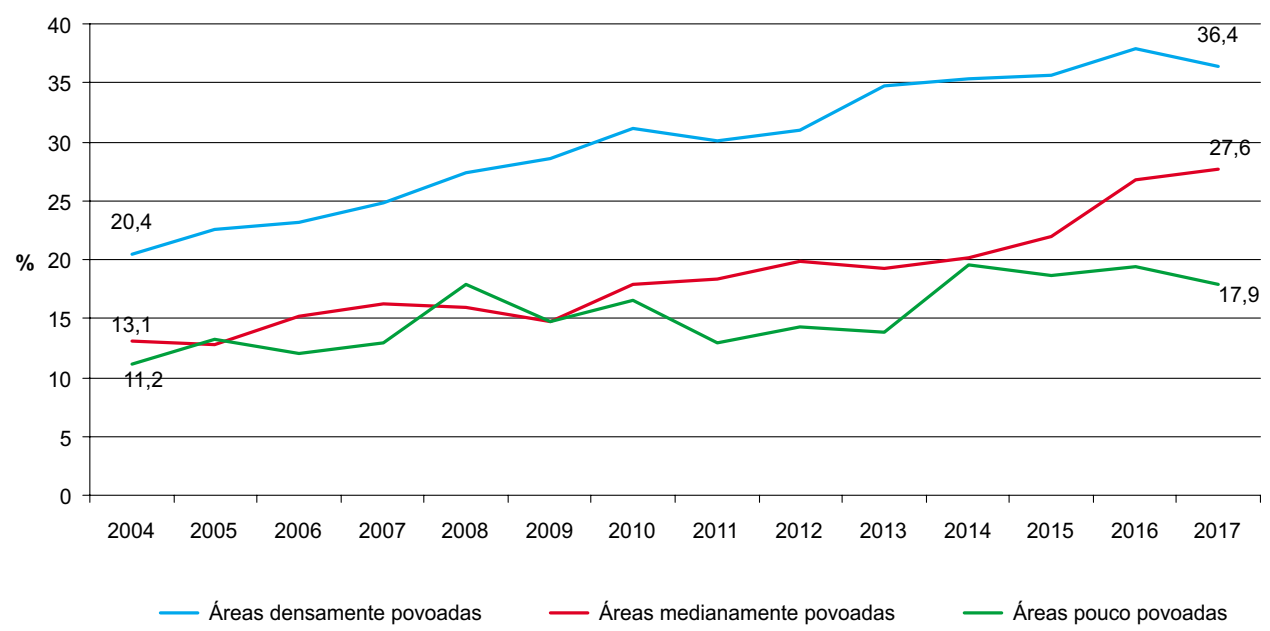

Figura 12 Qualificação superior da geração mais jovem em Portugal

Notas: quebra de série em 2012

Fonte dos dados: ICOR 2004 a 2017.

Fonte: Eurostat, julho de 2018 [código on-line edat_lfs_9913].

\section{Considerações finais}

O quadro teórico e a evidência quantitativa apresentados neste artigo sugerem algumas respostas às questões exploratórias colocadas na introdução.

Em primeiro lugar, ocorreram algumas alterações relevantes nos últimos 15 anos na diferenciação territorial observada da pobreza. Tendo em conta os indicadores relacionados com o rendimento monetário e os indicadores selecionados de privação no acesso a serviços, associados a necessidades ou funcionamentos generalizadamente valorizados, os dados sugerem a manutenção de uma situação potencialmente mais desfavorável nas áreas pouco povoadas, mas ao mesmo tempo, tendo sobretudo em conta a convergência das taxas de risco de pobreza observadas, uma diminuição da diferenciação entre áreas pouco povoadas e áreas densamente povoadas. As séries temporais dos indicadores de risco de pobreza e privação material sugerem também um efeito territorial diferenciado da recente crise económica (2009-2013) na configuração da pobreza, mais penalizador para as áreas densamente povoadas.

Em segundo lugar, a incoerência registada entre os indicadores baseados no rendimento e os baseados na privação material, com os primeiros a sugerir uma situação relativamente mais desfavorável nas áreas pouco povoadas e os segundos a sugerir uma situação relativamente mais desfavorável nas áreas muito povoadas, suscita 
efetivamente questões sobre a validade destes indicadores padrão para medir e comparar a pobreza em diferentes contextos territoriais. Importará neste contexto equacionar as opções metodológicas de observação, aferir a sua adequação na consideração das variações territoriais mais sistemáticas da conversão do rendimento em capacidade e prosseguir o caminho necessário de aperfeiçoamento dos indicadores utilizados na observação da pobreza, no espaço do rendimento e dos bens e serviços.

Em terceiro lugar, quer o quadro teórico quer os dados apresentados sugerem uma relação complexa entre contextos territoriais e pobreza. Em particular, por um lado, os indicadores relacionados com o rendimento monetário, a privação no acesso a serviços e a realização de funcionamentos generalizadamente valorizados, nomeadamente na área da saúde e da educação, sugerem uma maior vulnerabilidade à pobreza e exclusão nas áreas pouco povoadas. Por outro lado, os indicadores observados relacionados com a satisfação com a vida sugerem a existência de um efeito protetor e inclusivo associado às áreas pouco povoadas.

Finalmente, o conjunto dos dados observados evidenciam a importância dos contextos territoriais na configuração da pobreza e permite-nos sugerir uma resposta positiva à quarta questão colocada na introdução. Ou seja, na atualidade, contextos territoriais diferentes continuam a fazer a diferença na pobreza em Portugal. Destacam-se, em particular, as sugeridas desigualdades territoriais nas oportunidades reais para realizar funcionamentos generalizadamente valorizados, a que se associa uma situação de maior desvantagem nas áreas pouco povoadas, com implicações na configuração da pobreza a montante.

\section{Notas}

Por decisão pessoal, o texto foi escrito segundo o novo acordo ortográfico.

1 Nesta janela temporal, a classificação rural/urbano dos agregados populacionais adotada difere de estudo para estudo, de acordo com a informação disponibilizada pelo INE nas bases de microdados respetivas (ver Pereira, 2010a, pp. 118-119).

2 O grau de urbanização corresponde, neste caso, à classificação territorial em vigor, proposta pelo Eurostat, que divide o território dos Estados-Membros em três categorias: zonas densamente povoadas, zonas medianamente povoadas e zonas pouco povoadas (para uma breve apresentação desta tipologia, ver aspetos metodológicos deste artigo).

3 Ver, por exemplo, Weck e Lobato (2015).

4 Considerando esta alteração no método de classificação importa conhecer o impacto da mesma. Em Portugal, a utilização do novo método originou uma alteração pequena na distribuição populacional pelas três categorias, mais 2 pontos percentuais da população nas áreas densamente povoadas e nas áreas pouco povoadas e menos 5 pontos percentuais nas áreas medianamente utilizadas, a que se 
associa uma alteração na classificação de $30 \%$ da população (Dijkstra \& Poelman, 2014, pp. 11-12).

5 O rendimento monetário líquido corresponde ao valor do rendimento monetário obtido ao longo de um ano pelos agregados e seus membros, provenientes de diversas fontes, depois de deduzidos os impostos que sobre eles incidem e as contribuições para a segurança social (INE, 2016). O índice de necessidades relativas tem por base a escala de equivalência modificada da OCDE que atribui um ponderador de 1 ao primeiro indivíduo com 14 ou mais anos de um agregado; 0,5 aos restantes membros com 14 ou mais anos e 0,3 a cada criança, menor de 14 anos, do agregado.

As despesas com a habitação incluem "despesas relacionadas com a renda, água, eletricidade, gás ou outros combustíveis, condomínio, saneamento, manutenção e pequenas reparações, bem como juros relativos ao crédito à habitação principal e seguros." (INE, 2016, p. 94).

7 A interpretação dos resultados obtidos com este indicador deve ser realizada com especial cautela. Em particular, as despesas com habitação são uma das despesas onde se registam importantes economias de escala no consumo. A consequência de usar a mesma escala de equivalência que é usada para o rendimento antes de deduzidos os custos com a habitação é a de subestimação relativa do rendimento necessário para agregados com mais de um indivíduo.

8 Os nove itens selecionados correspondem a: a) capacidade para assegurar o pagamento imediato de uma despesa inesperada e próxima do valor mensal da linha de pobreza (sem recorrer a empréstimo); b) capacidade para pagar uma semana de férias, por ano, fora de casa, suportando a despesa de alojamento e viagem para todos os membros do agregado; c) capacidade para pagar atempadamente rendas, prestações de crédito ou despesas correntes da residência principal, ou outras despesas não relacionadas com a residência principal; d) capacidade para ter uma refeição de carne ou de peixe (ou equivalente vegetariano), pelo menos de 2 em 2 dias; e) capacidade para manter a casa adequadamente aquecida; f) posse de máquina de lavar roupa; g) posse de televisão a cores; $h$ ) posse de telefone fixo ou telemóvel; i) posse de automóvel (ligeiro de passageiros ou misto) (INE, 2016, p. 103). No caso dos últimos quatro itens, a privação só é considerada como tal se for indicado que a mesma se deve a dificuldades económicas (e não por outras razões).

9 Os treze itens selecionados incluem seis dos itens utilizados anteriormente, tendo sido excluídos os itens máquina de lavar a roupa, televisão a cores e telefone fixo ou telemóvel. Os sete itens adicionados são: a) substituir roupa usada por alguma roupa nova (excluindo a roupa em segunda mão); b) posse de dois pares de sapatos de tamanho adequado (incluindo um par de sapatos para todas as condições meteorológicas); c) gastar semanalmente uma pequena quantia de dinheiro consigo próprio; d) participação regular numa atividade de lazer (desporto, cinema, concerto, etc.); e) encontrar-se com amigos/familiares para uma bebida/refeição pelo menos uma vez por mês; f) acesso à internet para uso pessoal em casa; e g) possibilidade de substituir o mobiliário usado. No caso destes sete itens, a privação só é considerada como tal se for indicado que a mesma se deve a 
dificuldades económicas. Embora a seleção dos treze itens tenha sido sujeita a um rigoroso processo de aferição da sua adequação, validade e fiabilidade, subsistem problemas com alguns dos itens (ver Guio, Gordon, Nahera, \& Pomati, 2017).

10 No primeiro caso, por exemplo, Guio, Gordon, Nahera e Pomati (2017, pp. 26-27) identificam diferenças significativas nas respostas dadas aos itens utilizados para medir a privação associadas ao escalão etário, depois de controlado o efeito do rendimento. No segundo caso, por exemplo, Pereira (2010a, pp. 257-258) sugere uma menor relevância (relativa) do carro, quer para os indivíduos a viver sós com 65 ou mais anos quer em contextos muito urbanos e de acessibilidade muito alta.

11 A base de dados on-line do Eurostat não disponibiliza dados sobre a taxa de privação material desagregada pelo grau de urbanização, pelo que se recorre aqui a uma publicação do INE de 2010, que apresenta estes dados até 2009.

12 Refira-se aqui que tendo em conta uma composição demográfica diferenciada nas diferentes áreas, uma eventual inadequação da escala de equivalência utilizada para tornar o rendimento comparável entre ADPs com diferentes composições e dimensões (sugerida por Pereirinha, Pereira, Branco, Amaro, Costa \& Nunes, 2017) pode igualmente justificar parte da incoerência observada.

13 As inconsistências entre os indicadores de observação da pobreza e, em particular, as discordâncias encontradas na identificação dos indivíduos em situação de pobreza que resultam da escolha de indicadores de observação indireta e direta têm sido objeto de atenção na literatura (ver Pereira, 2010a, pp. 33-47). No estudo realizado por Pereira (2010a), é apresentada uma caracterização dos indivíduos que não são identificados de forma consistente pelos dois tipos de observação em Portugal Continental e com base nesta e na literatura são propostas explicações mais detalhadas para a existência dessa inconsistência.

\section{Referências}

Atkinson, A., Guio, A.-C., \& Marlier, E. (2017). Monitoring social inclusion in Europe. Luxemburgo: Publications Office of the European Union.

Blank, R. M. (2005). Poverty, policy, and place: How poverty and policies to alleviate poverty are shaped by local characteristics. International Regional Science Review, 28(4), 441-464.

Boarini, R., Comola, M., Smith, C., Manchin, R., \& Keulenaer, F. D. (2012). What makes for a better life?: The determinants of subjective well-being in OECD countries - Evidence from the gallup world poll (OECD Statistics Working Papers, 2012/03). OCDE Publishing.

Cotter, D. (2002). Poor people in poor place: Local opportunity structures and household poverty. Rural Sociology, 67(4), 534-555.

Dijkstra, L., \& Poelman, H. (2014). A harmonised definition of cities and rural areas: The new degree of urbanization (Regional Working paper 01/2014). European Commission Regional and Urban Policy. 
Eurostat. (2011). Eurostat regional yearbook 2011. Luxemburgo: Publications Office of the European Union.

Eurostat. (2018). Income and living conditions database. Eurostat Database. Disponível em https:/ / ec.europa.eu/eurostat/web/income-and-living-conditions/data/database

Guio, A.-C., Gordon, D., Nahera, H., \& Pomati, M. (2017). Revising the EU material deprivation variables. Luxemburgo: Publications Office of the European Union.

INE - Instituto Nacional de Estatística. (2010). Sobre a pobreza, as desigualdades e a privação material em Portugal. Lisboa: Instituto Nacional de Estatística.

INE - Instituto Nacional de Estatística. (2016). Inquérito às condições de vida e rendimento: Documento metodológico, versão 3.6. INE. Disponível em http:/ / smi.ine.pt/UploadFile/Download/1983

Lister, R. (2015). "To count for nothing": Poverty beyond the statistics. Journal of the British Academy, 3, 139-165.

Milbourne, P. (2014). Poverty, place, and rurality: Material and sociocultural disconnections. Environmental and Planning A, 46, 566-580.

Milbourne, P., \& Doheny, S. (2012). Older people and poverty in rural Britain: Material hardships, cultural denials and social inclusions. Journal of Rural Studies, 28(4), 389-397.

OECD. (2013). OECD guidelines on measuring subjective well-being. Paris: OECD Publishing.

Osier, G., Berger, Y., \& Goedemé, T. (2013). Standard error estimation for the EU-SILC indicators of poverty and social exclusion. Luxemburgo: Publications Office of the European Union.

Pereira, E. (2010a). Pobreza e ruralidade: Uma análise espacial em Portugal Continental (Tese de doutoramento). Universidade Técnica de Lisboa, Lisboa.

Pereira, E. (2010b). Observar a pobreza em Portugal: Uma leitura crítica das principais abordagens à operacionalização do conceito de pobreza. Forum Sociologico, (20), 57-66.

Pereira, E. (2010c). Contextos territoriais diferentes fazem a diferença no risco de pobreza em Portugal?. Revista Sociedade e Trabalho, 41, 111-124.

Pereira, E., Queiroz, C., Pereira, H., \& Vicente, L. (2005). Ecosystem services and human well-being: A participatory study in a mountain community in Portugal. Ecology and Society, 10(2), 14.

Pereirinha, J., Pereira, E., Branco, F., Amaro, I., Costa, D., \& Nunes, F. (julho de 2017). Rendimento adequado em Portugal: Quanto é necessário para uma pessoa viver com dignidade em Portugal?. Obtido de Rendimento Adequado em Portugal. Disponível em http:/ / www.rendimentoadequado.org.pt

Ravallion, M. (1998). Poor areas. In D. Giles, \& A. Ullah (Eds.), The handbook of applied economic statistics (pp. 63-91). Nova Iorque: Marcel Dekker.

Robeyns, I. (2005). The capability approach: A theoretical survey. Journal of Human Development, 6(1), 93-117.

Sen, A. (1981/1999). Pobreza e fomes: Um ensaio sobre direitos e privações. Lisboa: Terramar. Sen, A. (1983). Poor relatively speaking. Oxford Economic Papers, 35, 153-169.

Sen, A. (1992). Inequality reexamined. Oxford: Clarendon Press. 
Sen, A. (1999/2000). Desenvolvimento como liberdade. São Paulo: Companhia das Letras.

Small, M., Harding, D., \& Lamont, M. (2011). Reavaliando a cultura da pobreza. Sociologia \& Antropologia, 1(2), 91-118.

Subramanian, S., \& Duncan, C. (2000). Capability and contextuality (Working Paper Series, 10(10)). Harvard Center for Population and Development Studies.

Swidler, A. (1986). Culture in action: Symbols and strategies. American Sociological Review, 51(2), 273-286.

Weber, B., Jensen, L., Miller, K., Mosley, J., \& Fisher, M. (2005). A critical review of rural poverty literature: Is there truly a rural effect?. International Regional Science Review, 28(4), 381-414.

Weck, S., \& Lobato, I. R. (2015). Social exclusion: Continuities and discontinuities in explaining local patterns. Local Economy, 30(7), 765-782.

Weziak-Bialowolska, D. (2016). Spatial variation in EU poverty with respect to health, education and living standards. Social Indicators Research, 125(2), 451-479.

Data de submissão: 24/10/2018 | Data de aceitação: 22/01/2019 